\title{
QUALIDADE DE VIDA DOS PROFISSIONAIS DE SAÚDE NO ENFRENTAMENTO À COVID-19
}

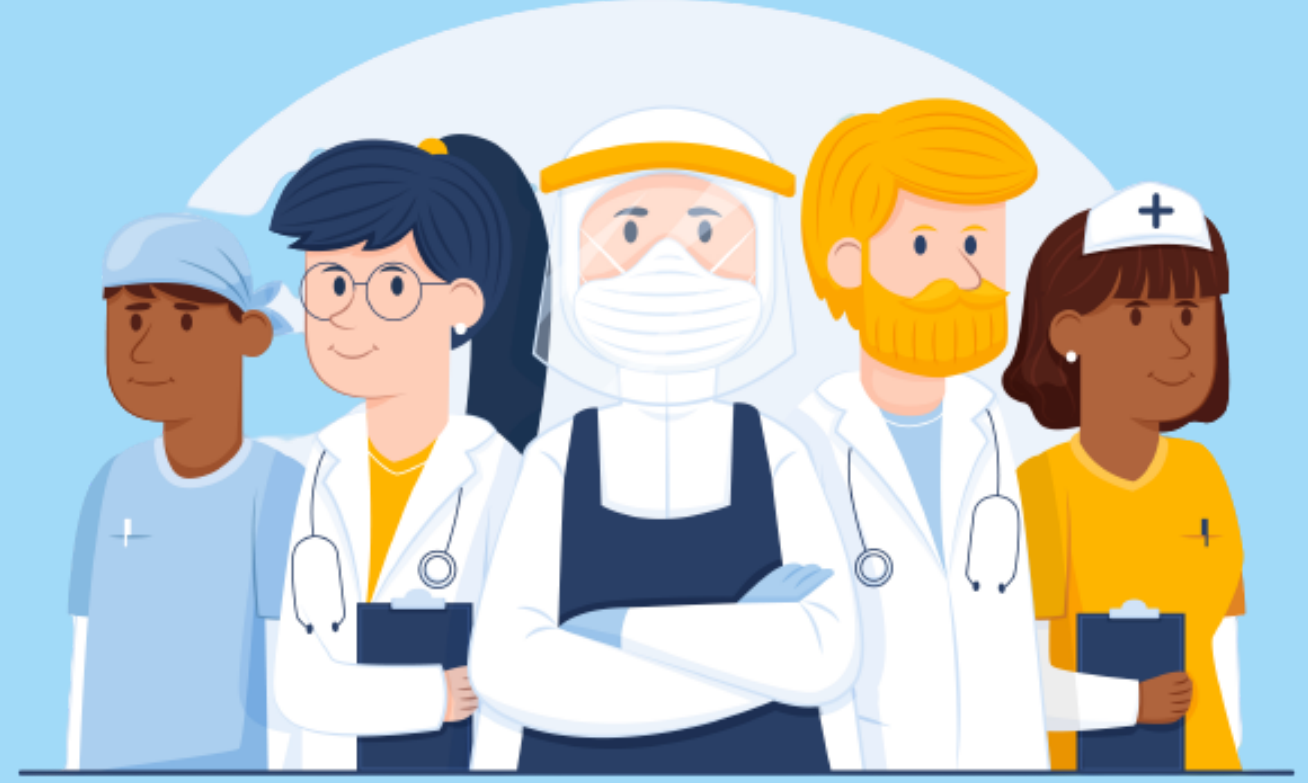

Covid-19

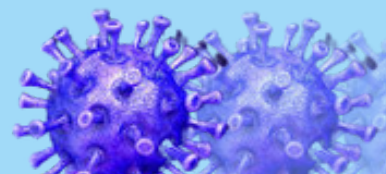

CORONAVÍRUS

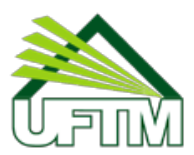


Copyright (C) 2020 - Todos os direitos reservados.

Projeto gráfico: Autores.

Imagens: Canvas.

Si381p Rezende, Isabela de Paula et al..

Qualidade de Vida dos Profissionais de Saúde no Enfrentamento à Covid-19 / Isabela de Paula Rezende et al.. São Carlos, 2020.

$26 \mathrm{p}$.

ISBN 978-65-5668-017-0

DOI: http://dx.doi.org/10.26626/978-65-5668-017$0.2020 B 0001$

1. COVID-19. 2. Enfermagem. 3. Profissionais de Saúde 4. Ensino. I. Org. II. Título.

CDD 370

Revisão e Editoração

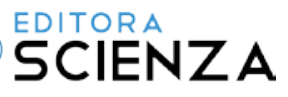

Rua Juca Sabino, 21 - São Carlos, SP

(16) 3364-3346 | (16) 9 9285-3689

www.editorascienza.com.br

gustavo@editorascienza.com 


\section{Autores}

Isabela de Paula Rezende

Muriele Pereira Mendes Cornélio

Ana Claudia Vieira de Almeida

Alana Fernandes Ribeiro

Daniel Pereira Rodrigues

Carolina Cassiano

Ingrid Fidelix de Souza

Ana Letícia Ribeiro Oliveira

Angélica Santana Lacerda

Leila Aparecida Kauchakje Pedrosa

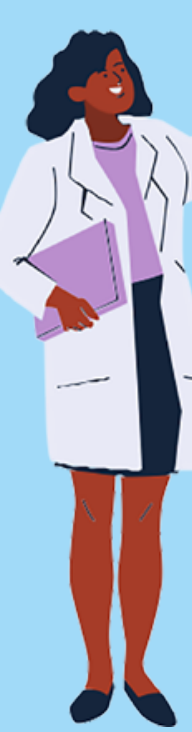

Financiamento:

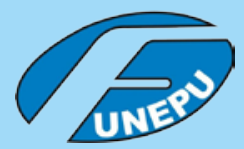




\section{Apresentação}

Este trabalho é produto de um projeto de extensão em interface com pesquisa, que foi desenvolvido pelo GRUPO DE PESQUISA "VIVER ADULTO E SAÚDE", certificado pelo CNPq e pela UFTM (Universidade Federal do Triângulo Mineiro), liderado pela Profa. Doutora Leila Aparecida Kauchakje Pedrosa e pela doutoranda Muriele Pereira Mendes Cornélio, com financiamento da FUNEPU (Fundação de Ensino e Pesquisa de Uberaba-MG), como bolsa de estudo da graduanda Isabela de Paula Rezende.

Foi aprovado pelo Comitê de Ética da UFTM e apresenta este e-book como produto e resultado dos objetivos traçados.

Esperamos que contribua para a promoção da saúde e da qualidade de vida dos profissionais da saúde!

Atenciosamente,

Leila Pedrosa e Muriele Cornélio 


\section{Sumário}

Introdução

6

Apresentação

1. O Impacto da Pandemia na Qualidade de Vida da População

2. A Qualidade de Vida do Profissional de Saúde no Contexto da Pandemia

2.1 Qualidade do Sono 14

2.2 Alimentação Equilibrada ..........................................

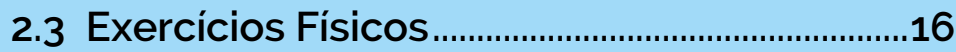

2.4 Relacionamentos Interpessoais.......................17

2.5 Espiritualidade ....................................................19

2.6 Saúde Mental....................................................... 20

2.7 Rede de Apoio Profissional e Familiar...........21

3. Autocuidado .22

Referências

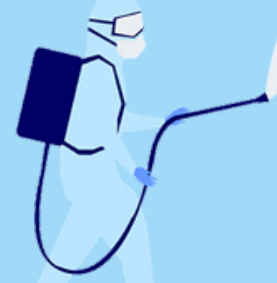




\section{Introdução}

O coronavirus (SARS-Cov2) foi identificado pela primeira vez na cidade de Wuhan, uma província de Hubei, na China, em 31 de dezembro de 2019, e é o causador da doença denominada COVID-19.
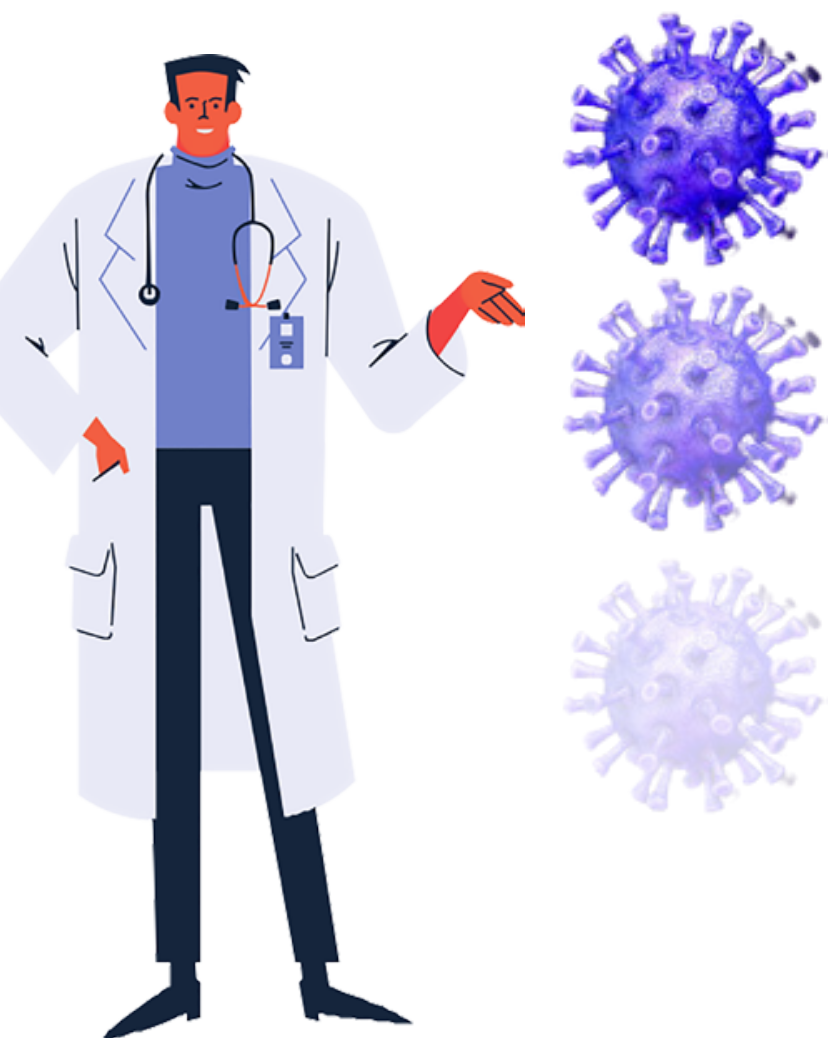

(OPAS, 2020; CASCELLA et al., 2020) 


\section{Apresentação}

Sintomas, como febre, acompanhados ou não de tosse seca, falta de ar, dor muscular, tontura, dor de cabeça, dor de garganta, coriza, dor no peito, diarreia, náusea e vômitos, cansaço, congestão nasal, conjuntivite, perda de paladar ou olfato, erupção cutânea na pele ou descoloração dos dedos das mãos ou dos pés, caracterizam a doença. Em suas formas mais críticas, provoca pneumonia grave, sepse e choque séptico.

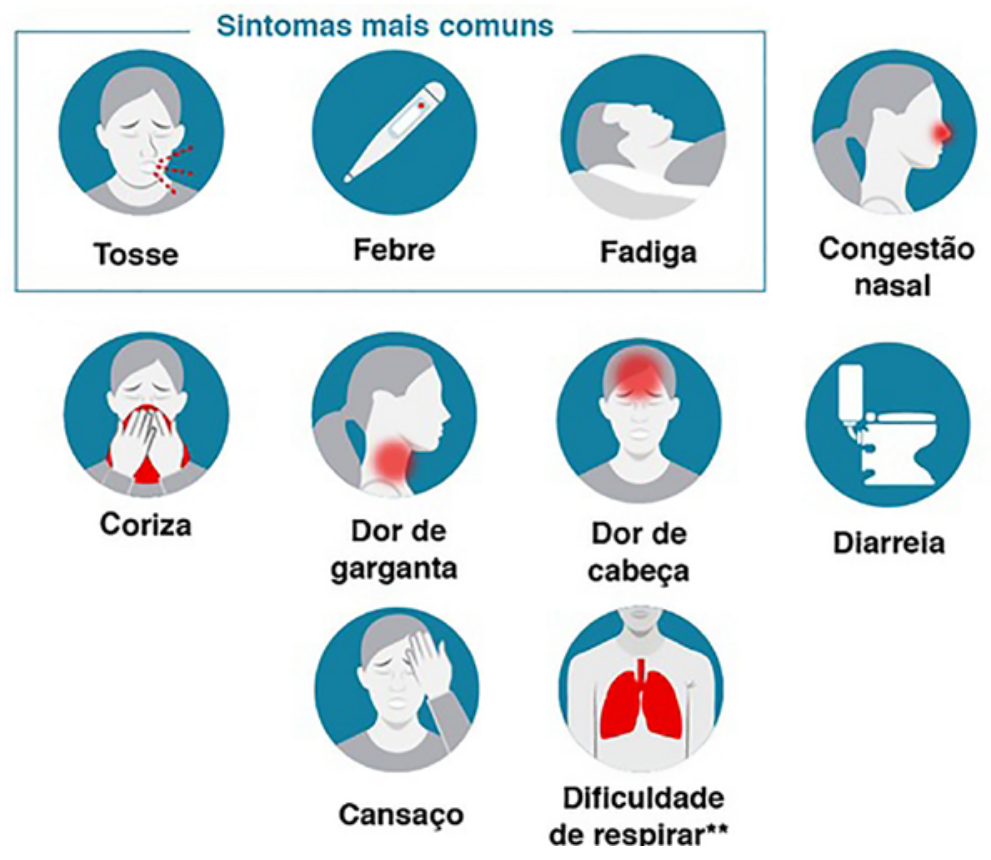

(OPAS, 2020; Yl et al., 2020) 


\section{A OMS definiu orientações}

de contenção da propagação do vírus por meio de diversas medidas:

- Higiene das mãos;

- Evitar aglomerações;

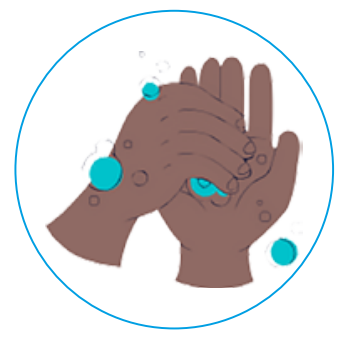

- Etiqueta respiratória;

- Uso de máscaras;

- Isolamento e tratamento de pacientes com sintomas;

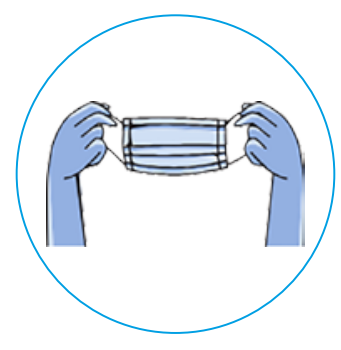

- Fechamento de locais públicos e outras medidas;

- Monitoramento de sintomas em contatos saudáveis;

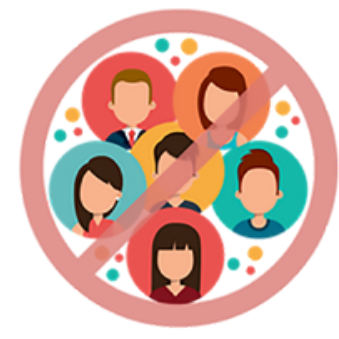

- Quarentena de saúde pública (contatos, assintomáticos) e/ou isolamento (indivíduos sintomáticos). 


\section{O IMPACTO DA PANDEMIA NA QUALIDADE DE VIDA DA POPULAÇÃO}

A expressão "qualidade de vida" abrange um conceito amplo, referente ao olhar do sujeito diante da satisfação individual em relação aos fatores de bem-estar, realização e crença pessoal, relacionamentos interpessoais, saúde, lazer, condições sociais e econômicas.

Em sua totalidade, englobam, de forma objetiva e subjetiva, a percepção do indivíduo em quatro pilares, que envolvem condições físicas, emocionais e socioeconômicas da própria vivência. A influência desses aspectos servem como parâmetro de avaliação da qualidade de vida.
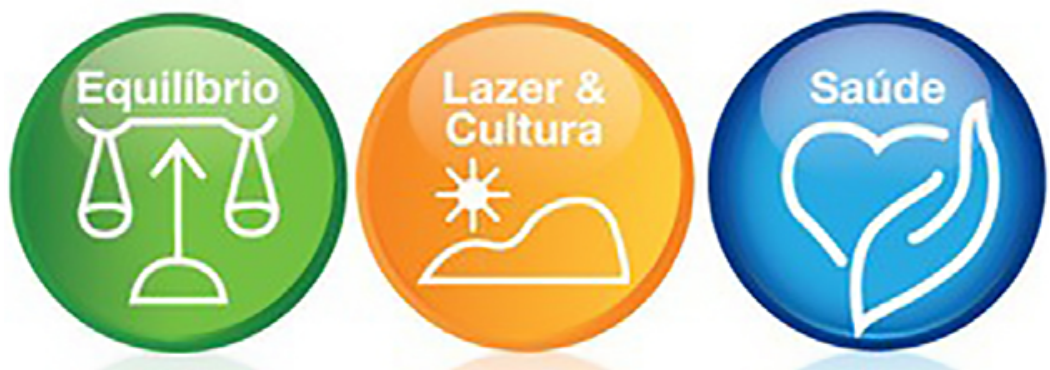

(BEZERRA et al., 2020) 


\section{O IMPACTO DA PANDEMIA NA QUALIDADE DE VIDA DA POPULAÇÃO}

A emergência do coronavírus, rapidamente, tornou-se um problema de saúde pública global, que levou a população a uma condição clínica ainda mais frágil, com consequências para a sanidade física e mental, afetando especialmente a população mais vulnerável.

Pode-se esperar alterações comportamentais negativas, desencadeadas pelo medo, reações de angústia, aumento do uso de substâncias, como o tabaco e o álcool, além de distúrbios de saúde mental, como ansiedade, depressão e somatização, entre várias outras consequências à saúde.

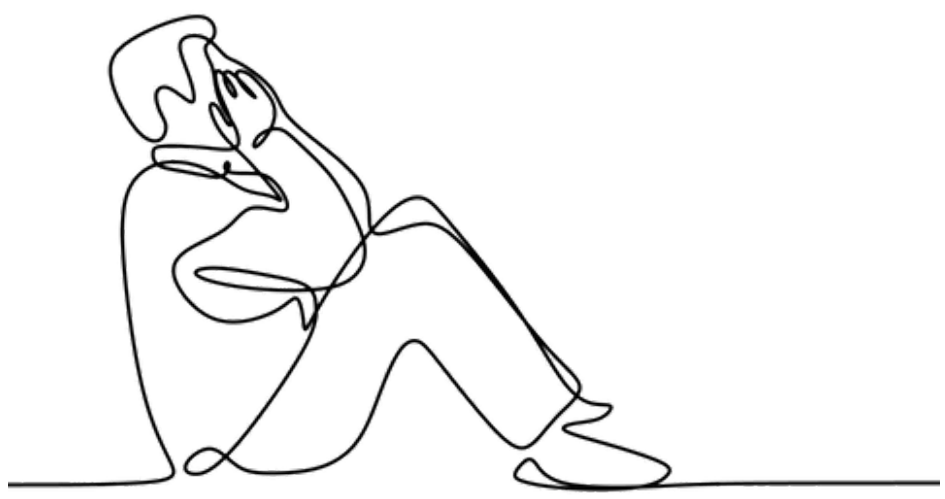

(SOARES et al., 2020; YANG et al., 2020) 


\section{A QUALIDADE DE VIDA DO PROFISSIONAL DE SAÚDE NO CONTEXTO DA PANDEMIA}

Os profissionais de saúde, devido à natureza essencial de seu trabalho, estão mais expostos ao risco de contaminação pelo coronavírus do que trabalhadores de outras profissões essenciais.

De modo geral, são vários os fatores que interferem na qualidade de vida dos profissionais
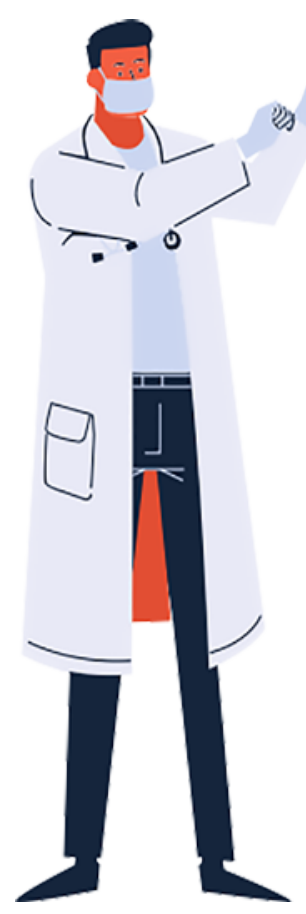
de saúde, sendo os aspectos -1) de domínio psicológico, como autoestima, espiritualidade, sentimentos positivos os mais afetados (FERIGOLLO et al., 2016).

\section{$O$ apoio adequado e} direcionado a cada população é necessário, especialmente à população vulnerável e a trabalhadores mais expostos. 


\section{A QUALIDADE DE VIDA DO PROFISSIONAL DE SAÚDE NO CONTEXTO DA PANDEMIA}

Os profissionais de saúde enfrentam condições diversas, capazes de favorecer o desgaste físico e psíquico (SANTANA, 2018), que é potencializado pelas consequências da pandemia.

Além da preocupação com o risco de contaminação, há relatos de afastamento dos familiares e da rede pessoal de suporte, a fim de minimizar os riscos de disseminação para essas pessoas (THE LANCET, 2020; ALMEIDA, 2020).

O trabalho, para os

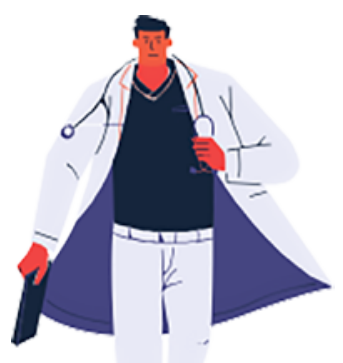
profissionais de saúde, agora, acarreta medo e insegurança pessoal (GODLEE, 2020).

Considerando tais condições, percebe-se a necessidade de promoção e de manutenção da qualidade de vida dos profissionais de saúde. Várias medidas podem favorecer a melhoria e a manutenção da qualidade de vida dos profissionais de saúde, com foco especial na saúde mental e alívio do estresse. 


\section{Cuide-se:}

- Pratique exercício físico;
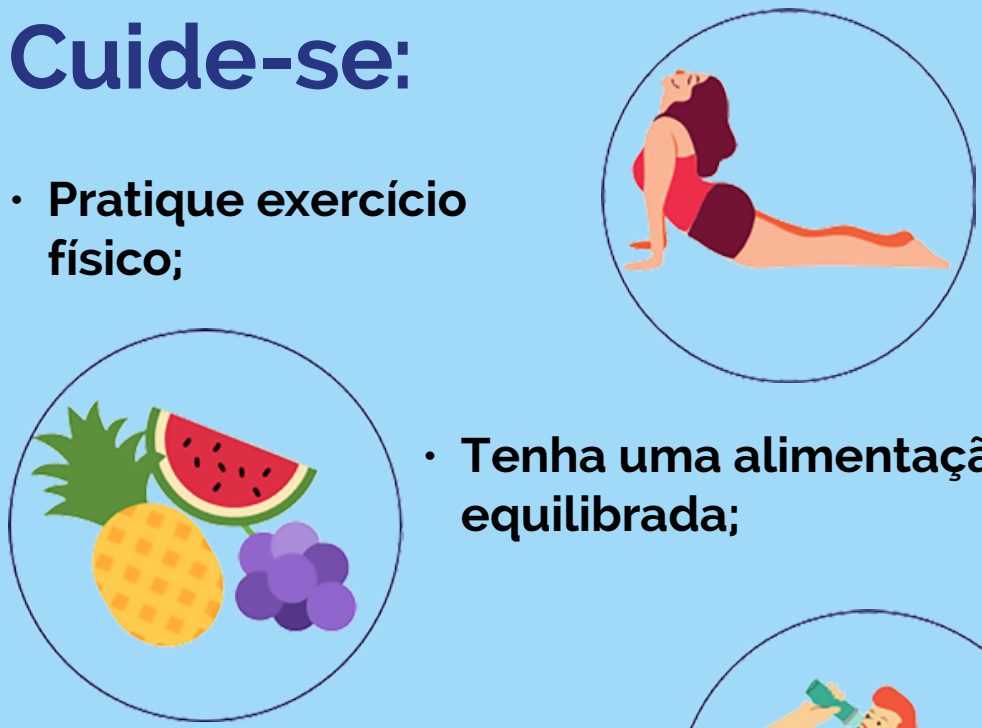

- Hidrate-se;

- Tenha uma alimentação equilibrada;

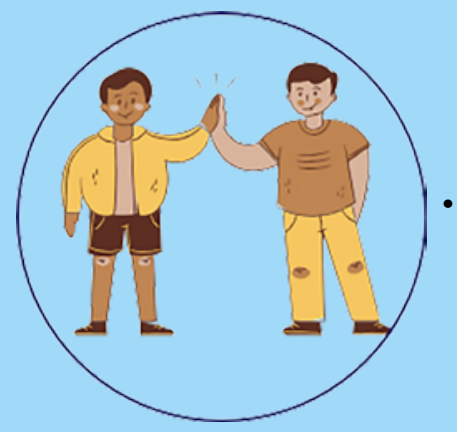

- Mantenha relações interpessoais com sua rede de apoio;

- Tenha um sono regular;
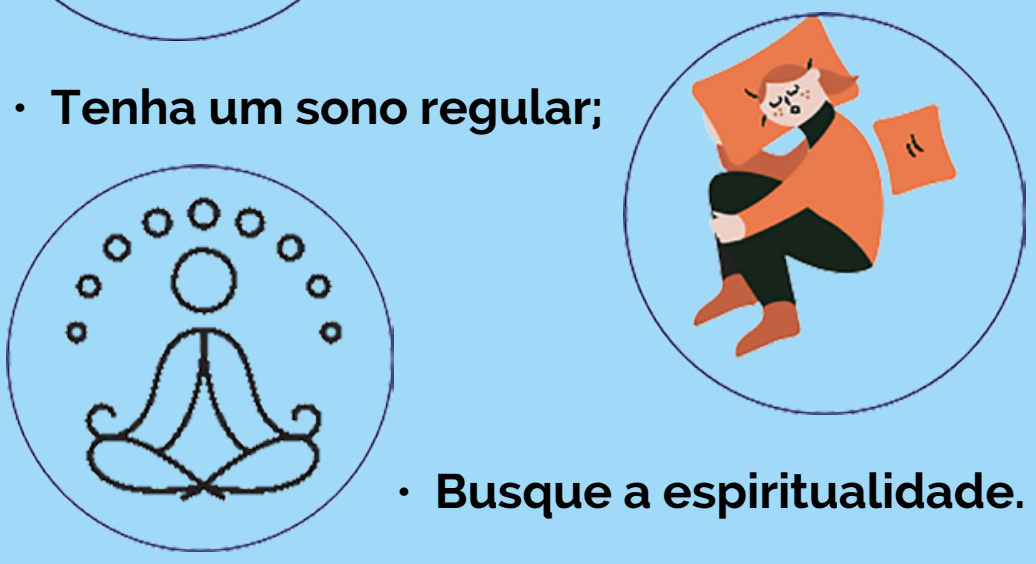

- Busque a espiritualidade. 


\subsection{QUALIDADE DO SONO}

O sono nos proporciona uma pausa das atividades perceptivos-sensoriais e das atividades motoras voluntárias, o que nos traz fortalecimento da memória, equilíbrio hormonal, benéfico ao funcionamento motor, serenidade e relaxamento.

A má qualidade do sono, por outro lado, traz malefícios na regulação de diversos sistemas no organismo, prejuízo à capacidade de memorização, cognição e desempenho motor, irritabilidade, cansaço, dores de cabeça, visão turva e alterações no metabolismo (REIS \& LOPES, 2020).
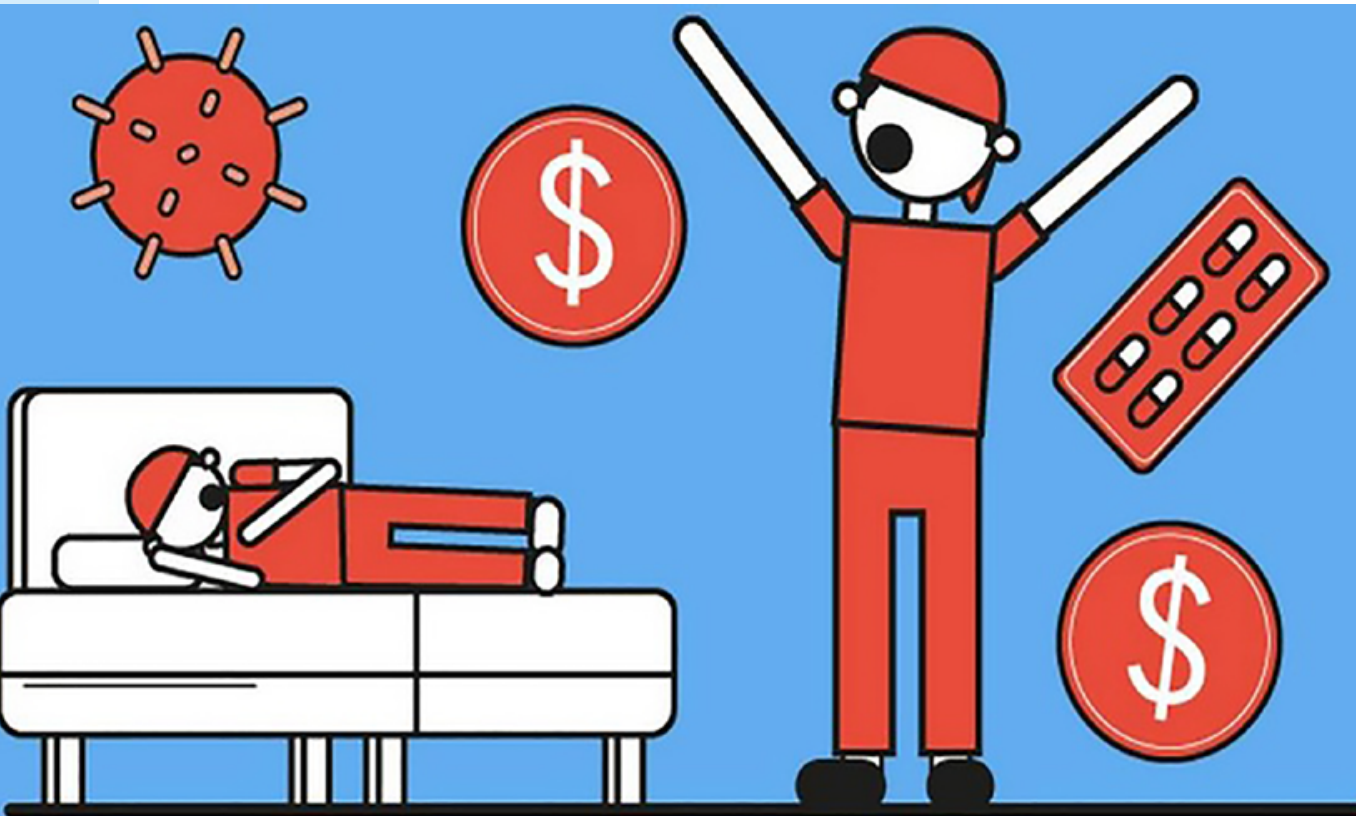


\subsection{ALIMENTAÇÃO EQUILIBRADA}

Uma alimentação saudável consegue promover a saúde e prevenir doenças. Ela deve ser diversificada, composta de alimentos com boa qualidade nutricional e em quantidades adequadas.

Deve ser constituida, principalmente, de alimentos in natura ou minimamente processados.

Os alimentos processados ou ultraprocessados devem ser consumidos de forma limitada e, sempre que possivel, evitados.

Sal, açúcares e gorduras devem ser consumidos em quantidades pequenas.

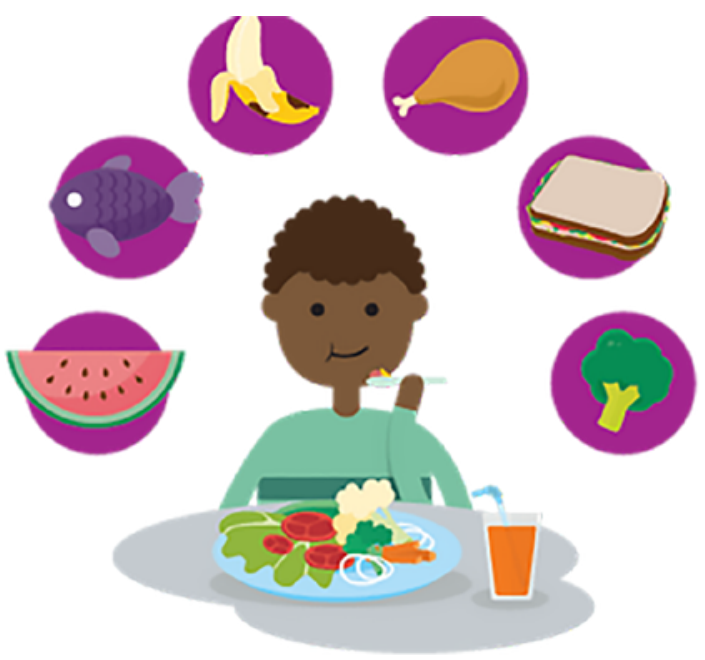

(GOIS et al., 2020) 


\subsection{EXERCÍCIOS FÍSICOS}

A prática de exercícios físicos se mostra como uma forma simples e barata para controlar os efeitos prejudiciais à saúde mental causados pelo distanciamento social, melhorando sintomas de ansiedade e depressão e ampliando emoções boas como a felicidade e o bem-estar (RAIOL, 2020).

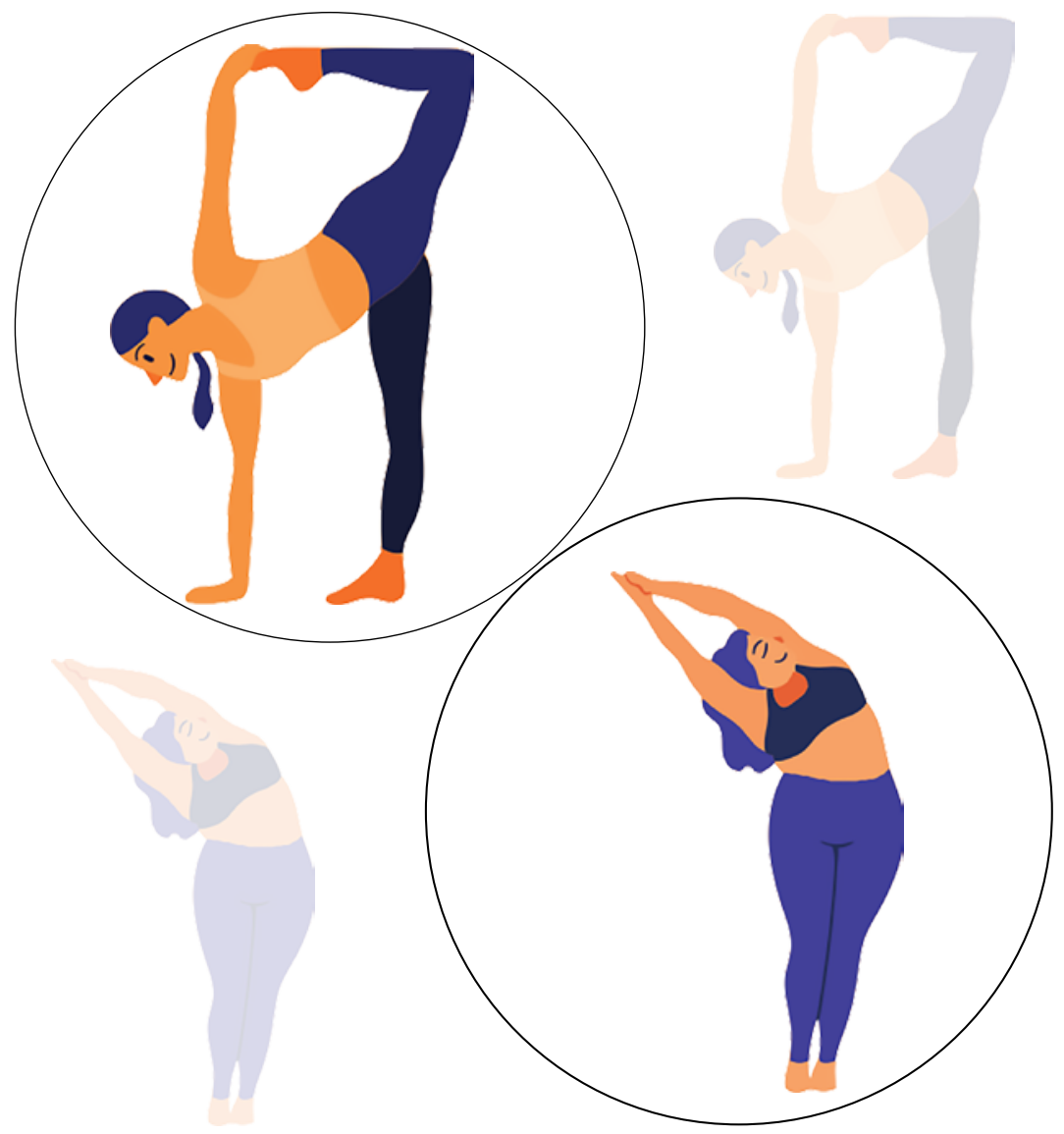




\subsection{RELACIONAMENTOS INTERPESSOAIS}

A maneira como as relações interpessoais são estabelecidas no ambiente de trabalho pode gerar hostilidade entre os trabalhadores, o que afeta a qualidade da assistência em saúde.

Para que isso não ocorra, é fundamental que a equipe desenvolva habilidades interativas e coloque em prática conceitos de comunicação verbal e não verbal, liderança, sintonia e objetividade (ABREU et al., 2017).
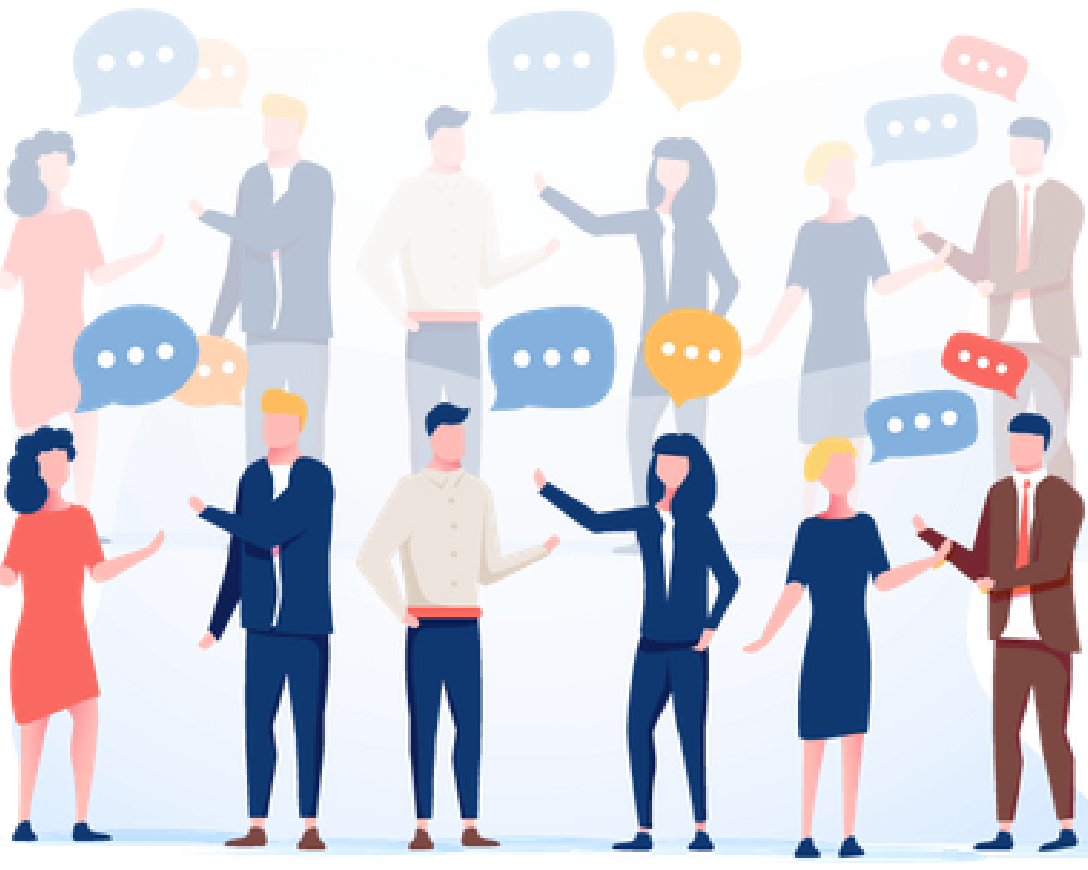


\section{RELACIONAMENTOS INTERPESSOAIS}

É essencial estabelecer uma comunicação eficaz entre os membros da equipe, pois é por meio dela que os profissionais expressam seus conceitos e sentimentos.

Isso reflete diretamente no cuidado profissional ofertado, consolidando a interação entre a equipe multiprofissional, clientes e seus familiares (MARTINS et al., 2014).

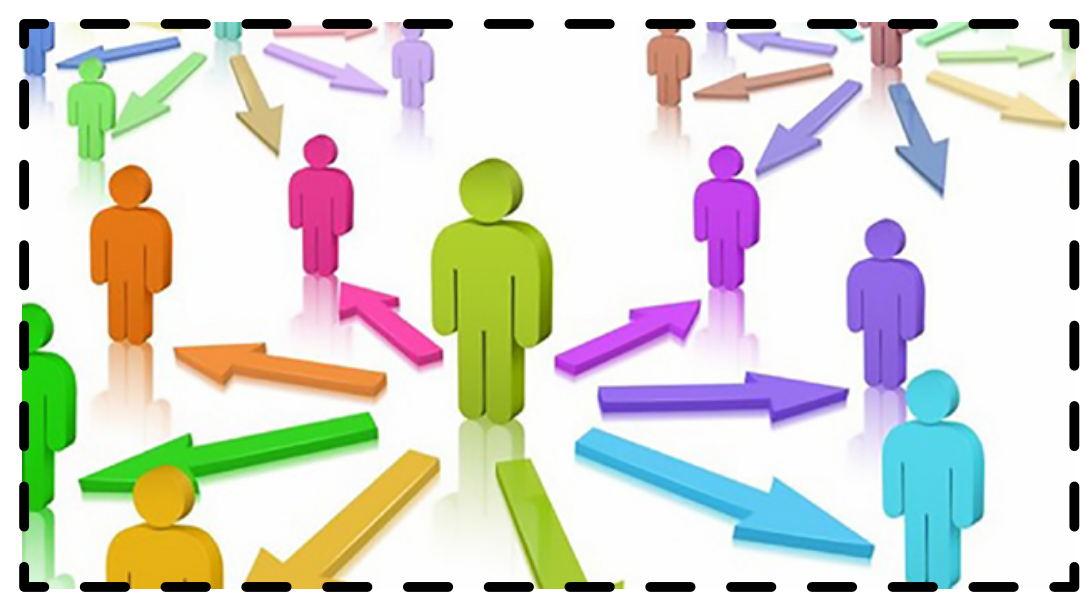




\subsection{ESPIRITUALIDADE}

A manifestação de espiritualidade, com foco na positividade e proteção, empatia e doação de si, favorece a pessoa e sua familia (TAVARES, 2020).

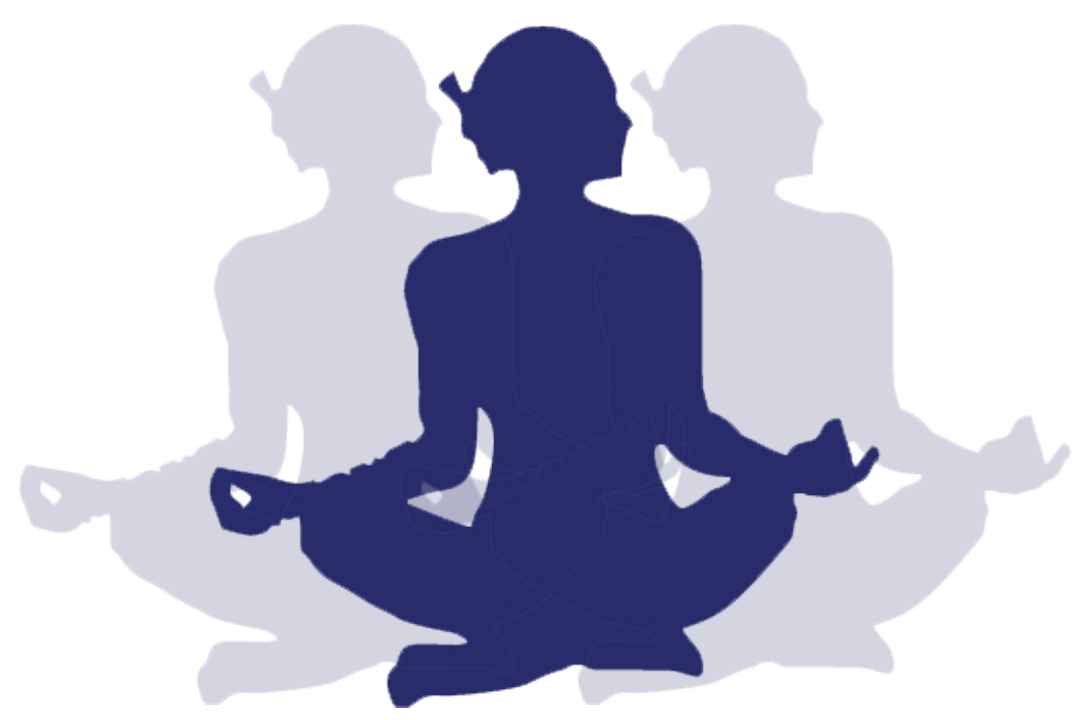

Segundo Campbell (2011), a espiritualidade orienta as escolhas que cada indivíduo toma, podendo incorporar crenças religiosas ou não.

A prática da espiritualidade adotada por profissionais da saúde os auxilia no enfrentamento de situações de desgaste emocional a que são expostos em sua rotina de trabalho (PILGER et al., 2014). 


\subsection{SAÚDE MENTAL}

Os profissionais de saúde mental têm papel fundamental em intervenções psicológicas na pandemia, minimizando impactos negativos e posteriormente na readaptação e manejo de mudanças e perdas (PEREIRA et al., 2020).

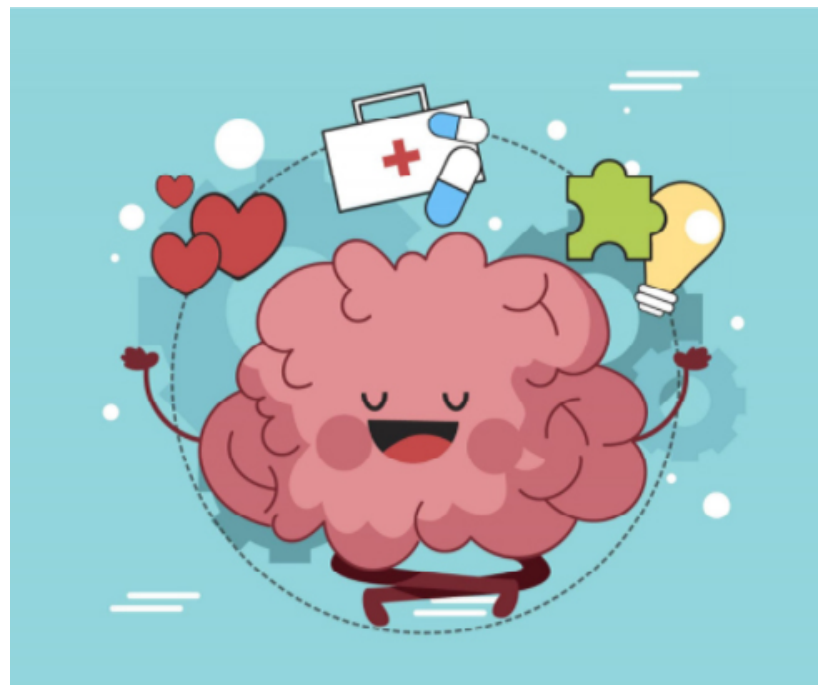

O acesso do profissional a materiais de saúde mental, recursos psicológicos na mídia, participação em aconselhamento ou psicoterapia demonstra a necessidade de cada profissional buscar uma estratégia que se conecte a sua realidade e que promova a diminuição do estresse e a melhoria da qualidade da sua saúde mental (SOUSA JÚNIOR et al., 2020). 


\subsection{REDE DE APOIO PROFISSIONAL E FAMILIAR}

Considerando a necessidade de se apoiar práticas de cuidados em saúde $e$, consequentemente, promover a qualidade de vida, vários grupos virtuais têm sido disponibilizados a toda a população, alguns com foco voltado aos profissionais da saúde.

No próprio local de trabalho, podem ser encontradas redes de apoio ao profissional de saúde que está na linha de frente do combate à pandemia de coronavirus (JULIANO et al., 2014).

A cooperação entre grupos também pode favorecer benefícios mútuos por meio de práticas solidárias

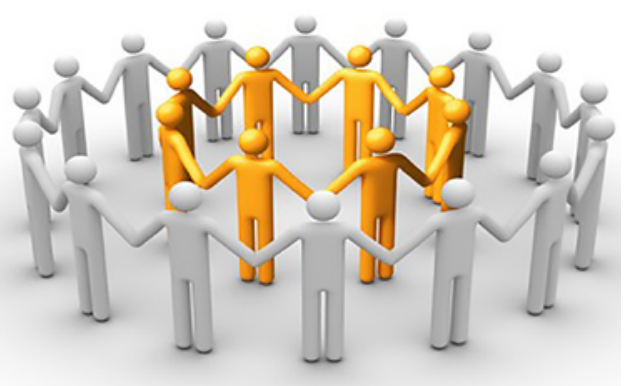
e parcerias, bem como a rede de relações familiares pode influenciar significativamente a qualidade das relações intrafamiliares, tão necessárias neste momento de isolamento social (BRASIL, 2020). 
4. Autocuidado

Quanto mais eu

cuido de mim,

melhor eu cuido

do outro!

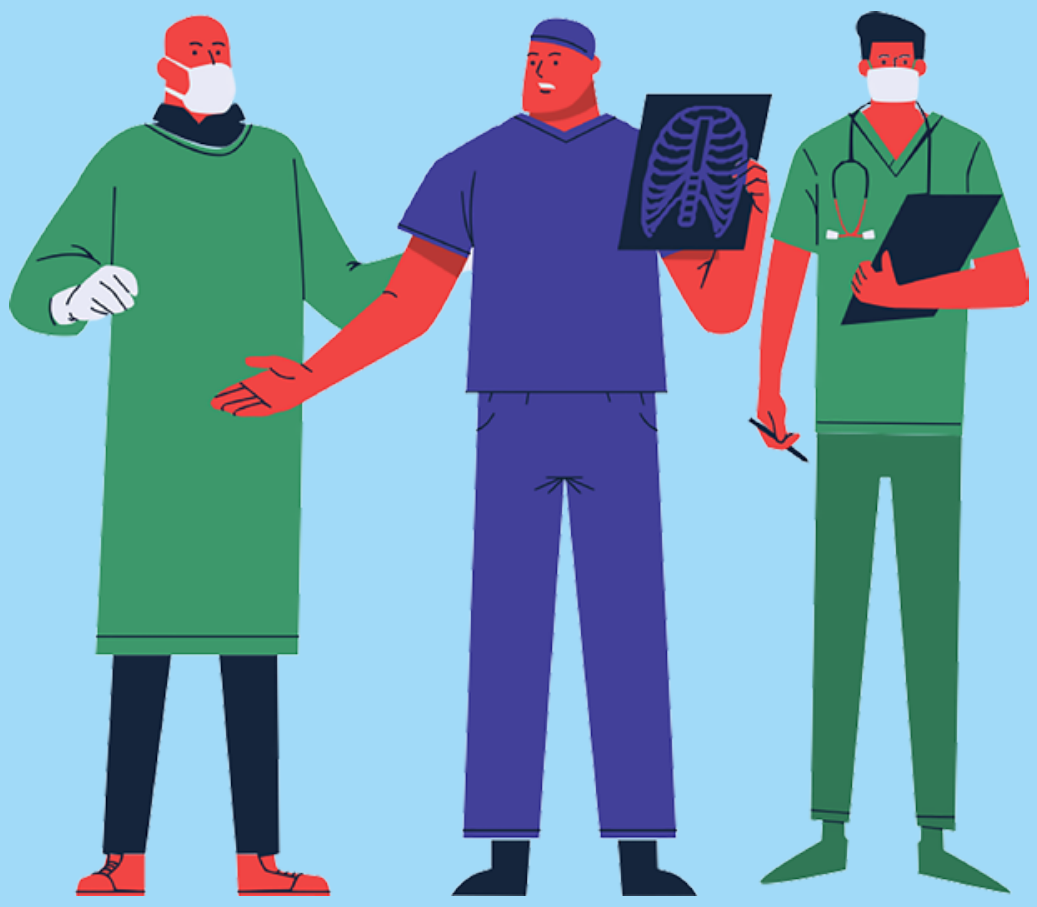




\section{Referências}

ABREU, Tatiana Fernandes Kerches; AMENDOLA Fernanda; TROVO Mônica Martins. Relational technologies as instruments of care in the Family Health Strategy. Rev Bras Enferm, v. 70, n. 5. p. 981-7. sep.-oct. 2017. Disponivel em: https://www.scielo.br/scielo. php?script=sci_arttext\&amp; pid=S0034- $\quad 71672017000500981$. Acesso em: 15 set 2020. DOI: http://dx.doi.org/10.1590/00347167-2016-0337.

ALMEIDA, Ildeberto Muniz de. Proteção da saúde dos trabalhadores da saúde em tempos deCOVID-19 e respostas à pandemia. Rev Bras Saude Ocup, São Paulo, v. 45. p. 1-10, 10 jun. 2020. Internet, Disponivel em: https://www.scielo.br/scielo.php?script=sci_ arttext\&amp;pid=S0303-76572020000101500.Acesso em: 15 set 2020. DOI: http://dx.doi.org/10.1590/scielopreprints.140,

BEZERRA, Anselmo César Vasconcelos; SILVA, Carlos Eduardo Menezes da; SOARES, Fernando Ramalho Gameleira; SILVA, José Alexandre Menezes da. Fatores associados ao comportamento da população durante o isolamento social na pandemia de COVID-19. Ciência \& Saúde Coletiva, Rio de Janeiro, v. 25, supl. 1 , p. 2411-21, jun. 2020. Disponivel em: https://www.scielo.br/pdf/ csc/v25s1/1413-8123-csc-25-s1-2411.pdf. Acesso em: 15 set 2020. DOl: http://dx.doi.org/10.1590/1413-81232020256.1.10792020,

BRASIL. Ministério da Saúde. Profissionais do SUS já podem contar com suporte psicológico. Disponivel em: http://antigo.saude. gov.br/noticias/agencia-saude/46906-profissionais-do-sus-japodem-contar-com-suporte psicologico\#: :text=J\%C3\%A1\%20 est\%C3\%A1\%20dispon\%C3\%ADvel\%200\%20servi\%C3\%A70,19\%20 em\%20todo\%200\%20pa\%C3\%ADs. Acesso em: 15 set 2020.

CAMPBELL, Margaret L. Nurse to nurse: cuidados paliativos em enfermagem. Ed. 1. Porto Alegre: Artmed, McGraw Hill, 2011.

CASCELLA Marco; RAJNIK, Michael; CUOMO, Arturo; DULEBOHN, Scott C.; DI NAPOLI, Raffaela. Recursos, avaliação e tratamento Coronavirus (COVID-19). StatPearls, 2020, updated 2020 aug. 10, Treasure Island (FL): StatPearls Publishing, Disponivel em: https://www.ncbi.nlm.nih.gov/books/NBK554776/. Acesso em: 15 set 2020 . 
FERIGOLLO, Juliana Prestes; FEDOSSE Elenir; SANTOS FILHA, Valdete Alves Valentins dos. Qualidade de vida de profissionais da saúde pública. Cad. Ter. Ocup. UFSCar, São Carlos, v. 24, n. 3. p. 497-507, 2016. Disponivel em: http://doi.editoracubo.com. br/10.4322/0104-4931.ctoAO0722. Acesso em: 15 set 2020. DOl: http://dx.doi.org/10.4322/0104- 4931.ctoAO0722,

GODLEE, Fiona. Protect our healthcare workers. BMJ, v. 369, n. 1324. Disponivel em: https://www.bmj.com/content/369/bmj.m1324, Acesso em: 15 set. 2020. DOl: https://doi.org/10.1136/bmj.m1324. GOIS, Bárbara Paixão de; PEREIRA, Arraída Dias; LOPES, Kairem Layss Soares; CORGOSINHO, Flávia Campos. Suplementação e alimentação adequada no contexto atual da pandemia causada pela COVID-19. Revista Desafios, v. 7. n. especial 3. Supl. COVID-19, p. 89-96, 2020. Internet, Disponivel em: https://sistemas.uft.edu. $\mathrm{br} /$ periodicos/index.php/desafios/article/view/8825/16733. Acesso em: 15 set 2020. DOl: http://dx.doi.org/10.20873/ uftsuple2020-8825,

JULIANO, Maria Cristina Carvalho; YUNES, Maria Angela Mattar. Reflexões sobre rede de apoio social como mecanismo de proteção e promoção de resiliência. Ambiente \& Sociedade, v. 17. n. 3. p. 135-54, jul.-set. 2014. Disponivel em: https://www.scielo.br/ pdf/asoc/v17n3/v17n3a09.pdf. Acesso em: 15 set 2020.

MARTINS, Cláudia Cristiane Filgueira; SANTOS, Viviane Euzébia Pereira; PEREIRA, Marta Silvânere; SANTOS, Natally Pereira. Relacionamento interpessoal da equipe de enfermagem $x$ estresse: limitações para a prática. Cogitare Enferm, v. 2, n. 19 , p. 309-15, abr.-jun. 2014. Disponivel em: https://revistas.ufpr.br/ cogitare/article/view/36985. Acesso em: 15 set 2020. DOl: http:// dx.doi.org/10.5380/ce.v19i2.36985,

ORGANIZAÇÃO PAN-AMERICANA DE SAÚDE. Resposta à transmissão comunitária de COVID-19. Orientação provisória. 7 de março de 2020. Internet, Disponivel em: https://iris.paho.org/ bitstream/handle/10665.2/51983/OPASBRACOVID1920038_ por.pdf? sequence=1\&isAllowed=y. Acesso em: 15 set 2020. 
PEREIRA, Mara Dantas; OLIVEIRA, Leonita Chagas de; COSTA, Cleberson Franclin Tavares; BEZERRA, Claudia Mara de Oliveira; SANTOS, Cristiane Kelly Aquino dos et al. A pandemia de COVID-19, o isolamento social, consequências na saúde mental e estratégias de enfrentamento: uma revisão integrative. Research, Society and Development, v. 9, n. 7. p.1- 35, 2020. Disponivel em: https://www.researchgate.net/publication/342135901_A_ pandemia_de_COVID19_o_isolame nto_social_consequencias_ na_saude_mental_e_estrategias_de_enfrentamento_uma_revis ao_integrativa. Acesso em: 15 set 2020. DOl: http://dx.doi. org/10.33448/rsd-vgi7.4548,

PILGER, Caliope; MACEDO, Jaqueline Queiroz de; ZANELATTO, Renata; SOARES, Letícia Gramazio; KUSUMOTA, Luciana. Percepção da equipe de enfermagem de uma unidade de terapia intensiva com relação à espiritualidade e religiosidade. Cienc Cuid Saude, v. 13, n. 3. p. 479-86, 2014. Disponivel em: http://www.periodicos.uem.br/ojs/index.php/CiencCuidSaude/ article/view/19788. Acesso em: 15 set 2020. DOl: https://doi. org/10.4025/cienccuidsaude.v13i3.19788.

RAIOL, Rodolfo A. Praticar exercícios físicos é fundamental para a saúde física e mental durante a Pandemia da COVID-19. Brazilian Journal of Health Review, v. 3. n. 2, p. 2804-13, 2020. Disponivel em: $\quad$ https://www.brazilianjournals.com/index.php/BJHR/ article/view/8463/7298. Acesso em: 15 set 2020.DOI: http:// dx.doi.org/10.34119/bjhrv3n2-124.

REIS, Michelle Cristina Guerreiro dos; LOPES, IsraelCardoso. Privação do sono em profissionais enfermeiros. TCC (enfermagem) Centro Universitário do Planalto Central Apparecido dos Santos Uniceplac, Brasilia, 2019. Internet, Disponivel em: https://dspace. uniceplac.edu.br/handle/123456789/302. Acesso em: 15 set 2020.

SOARES, Fernando Ramalho Gameleira; SILVA, José Alexandre Menezes da. Fatores associados ao comportamento da população durante o isolamento social na pandemia de COVID-19. Ciência \& Saúde Coletiva, v. 25, supl. 1, p. 2411-21, Rio de Janeiro, jun. 2020. Disponivel em: https://www.scielo.br/pdf/csc/v25s1/1413-8123csc-25-s1-2411.pdf. Acesso em: 15 set 2020. DOl: http://dx.doi. org/10.1590/1413-81232020256.1.10792020. 
SOUSA JÚNIOR, Belarmino Santos de; MENDONÇA, Ana Elza Oliveira de: ARAÚJO, Analice Campelo de: SANTOS, Rafael da Costa; DANTAS NETO, Francisco Assis; SILVA, Richardson Augusto Rosendo da. Pandemia do coronavirus: estratégias amenizadoras do estresse ocupacional em trabalhadores da saúde. Enfermagem em Foco, v. 11, n. 1 esp, p. 148-54, 2020. Disponivel em: http://revista.cofen.gov.br/index.php/enfermagem/article/ view/3644/818. Acesso em: 15 set 2020.

SANTANA, Leni de Lima. Riscos psicossociais e saúde mental em ambiente hospitalar: com a voz o trabalhador. 2018. Tese (Ciências da saúde) - Universidade Federal do Paraná, Curitiba, 2018. Disponivel em: https://Www. prppg.ufpr.br/siga/visitante/trabalhoConclusaoWS? l= 14957\&idprograma=40001016045P7\&anobase=2018\&idtc=79. Acesso em: 15 set 2020.

THE LANCET. COVID-19: protecting health-care workers. The Lancet, editorial, v. 395, p. 922, 2020. Disponivel em: https:// WWw.thelancet.com/journals/lancet/article/PIISO1406736(20)30644- 9/fulltext. Acesso em: 15 set 2020. DOI: http:// dx.doi.org/10.1016/S0140- 6736(20)30644-9.

TAVARES, Cássia Quelho. Dimensões do cuidado na perspectiva da espiritualidade durante a pandemia pelo novo coronavirus (COVID-19). Journal Health Npeps, v. 1, n. 5. p. 1-4, 2020. Disponivel em: http://docs.bvsalud.org/biblioref/2020/04/1095168/451715943-1-pb.pdf. Acesso em: 15 set 2020. DOl: http://dx.doi. org/10.30681/252610104517.

YANG, Yicheng: XIAO, Zhiqiang; YE, Kaiyan; HE, Xiaoen; SUN, Bo; QIN, Zhiran et al. SARS-CoV-2: characteristics and current advances in research. Virol J, v. 17, n 117, p. 17, 2020. Disponivel em: https://virologyj.biomedcentral.com/articles/10.1186/s12985020-01369- z\#citeas. Acesso em: 15 set 2020. DOl: http://dx.doi. org/10.1186/s12985-020- 01369-Z.

YI, Ye; LAGNITON, Philip N. P; YE, Sen; LI, Enqin; XU, Ren-He. COVID-19: what has been learned and to be learned about the novel coronavirus disease. International Journal of Biological Sciences, v. 10, n. 16, p. 1753-66, 2020, Disponivel em: https:// www.ncbi.nlm.nih.gov/pmc/articles/PMC7098028/. Acesso em: 15 set 2020. 